\title{
Coherent pathways for subduction from the surface mixed layer at ocean fronts
}

\author{
Mara Freilich $^{1}$, Amala Mahadevan ${ }^{2}$ \\ ${ }^{1}$ MIT-WHOI Joint Program in Oceanography/Applied Ocean Sciences and Engineering \\ ${ }^{2}$ Woods Hole Oceanographic Institution
}

\section{Key Points:}

- The dynamical pathways of subduction from the surface mixed layer to the pycnocline at a front are characterized using Lagrangian analysis.

- The pathways of subduction are influenced by mixed layer mesoscale (geostrophic) and submesoscale (ageostrophic) frontogenetic processes.

- Due to the influence of submesoscale along-front variability, subduction is coherent on submesoscale, $\sim 10 \mathrm{~km}$, length scales.

Corresponding author: Mara Freilich, maraf@mit.edu

This is the author manuscript accepted for publication and has undergone full peer review but has not been through the copyediting, typesetting, pagination and proofreading process, which may lead to differences between this version and the Version of Record. Please cite this article as doi: 10.1029/2020JC017042.

This article is protected by copyright. All rights reserved. 


\section{Abstract}

In frontal zones, water masses that are tens of kilometers in extent with origins in the mixed layer can be identified in the pycnocline for days to months. Here, we explore the pathways and mechanisms of subduction, the process by which water from the surface mixed layer makes its way into the pycnocline, using a submesoscale-resolving numerical model of a mesoscale front. By identifying Lagrangian trajectories of water parcels that exit the mixed layer, we study the evolution of dynamical properties from a statistical standpoint. Velocity- and buoyancy-gradients increase as water parcels experience both mesoscale (geostrophic) and submesoscale (ageostrophic) frontogenesis and subduct beneath the mixed layer into the stratified pycnocline along isopycnals that outcrop in the mixed layer. Subduction is transient and occurs in coherent regions along the front, the spatial and temporal scales of which influences the scales of the subducted water masses in the pycnocline. An examination of specific subduction events reveals a range of submesoscale features that support subduction. Contrary to the forced submesoscale processes that sequester low potential vorticity (PV) anomalies in the interior, we find that $\mathrm{PV}$ can be elevated in subducting water masses. The rate of subduction is of similar magnitude to previous studies ( $\sim 100 \mathrm{~m} /$ year), but the pathways that are unraveled in this study, along with the Lagrangian evolution of properties on water parcels, emphasize the role of submesoscale dynamics coupled with mesoscale frontogenesis.

\section{Plain Language Summary}

Exchange of properties such as heat, carbon, and nutrients between the ocean surface and the interior has implications for ocean circulation and ecosystems. But the sharp increase in density below the well-mixed surface layer inhibits the transport of these waters into the region of increasing density that lies beneath, except along sloping surfaces of constant density, or fronts. Here, using a three-dimensional computational model of an ocean front, we track and study the properties of water as it exits the surface mixed layer and travels deeper in a process we call subduction. The subduction occurs in specific regions, at scales $\lesssim 10 \mathrm{~km}$, where the horizontal density variation is strongest. This study unravels important pathways for exchange between the ocean surface and interior that are not included in global models and result in $100 \mathrm{~m}$ of the mixed layer being subducted over the course of a year.

\section{Introduction}

The exchange of properties between the ocean and atmosphere, including heat, carbon, and oxygen, is affected by subduction, which is the transport of water from the sur- 
face mixed layer into the stratified pycnocline. Subduction ventilates the pycnocline, affects the water mass characteristics of the interior, and impacts the ocean's biogeochemistry. The seasonal transformation of the mixed layer and the large-scale circulation (Nurser \& Marshall, 1991; Lévy et al., 2013) leads to subduction through diabatic processes. In addition, subduction occurs along sloping isopycnals at fronts, where mixed-layer enhanced submesoscale processes enhance vertical advection on horizontal scales of 0.1-10 km (Bosse et al., 2015; Omand et al., 2015; Klymak et al., 2016; Stanley et al., 2017; Wenegrat et al., 2018; Freilich \& Mahadevan, 2019).

Large vertical velocities in the mixed layer can arise from a range of submesoscale processes (Haine \& Marshall, 1998; Mahadevan \& Tandon, 2006; McWilliams, 2016). These include mixed layer instability (Fox-Kemper et al., 2008), submesoscale frontogenesis in the mixed layer (Thomas et al., 2008; Barkan et al., 2019), and boundary forced submesoscale dynamics, such as non-linear Ekman pumping and surface-forced symmetric instability (Thomas et al., 2013). Submesoscale flows generate vertical velocities of $\mathcal{O}(100) \mathrm{m}$ $\mathrm{d}^{-1}$ (Fox-Kemper et al., 2008; Mahadevan et al., 2010) and are characterized by large, $O(1)$, Rossby number, and low (also $O(1))$ Richardson number. The downward velocities due to submesoscale dynamics are larger in magnitude and concentrated in smaller regions than the upward velocities (Shcherbina et al., 2015). Within the mixed layer, submesoscale flows coexist with boundary layer turbulent motion, which can generate vertical velocities of $\mathcal{O}(1000) \mathrm{m}_{-} \mathrm{d}^{-1}$ within the mixed layer and is resolved by large eddy simulations (LES) (Skyllingstad et al., 2017; Verma et al., 2019) and observed with Lagrangian instruments (DAsaro et al., 2018).

Submesoscale instabilities are generally enhanced in the mixed layer, but the vertical density gradient (stratification) at the base of the mixed layer is typically greater than in the pycnocline and vertical transport across the mixed layer base is inhibited. However, submesoscale dynamics also has an influence below the surface mixed layer. Symmetric instability mixes momentum and tracers along isopycnal surfaces, often reaching below the mixed layer (Thomas et al., 2013) and leading to exchange of tracers between the surface and pycnocline (Smith et al., 2016; Erickson \& Thompson, 2018; Archer et al., 2020). Submesoscale mixed layer eddies can also barotropize and induce alongisopycnal stirring in the pycnocline (Badin et al., 2011). Furthermore, recent observational and modeling studies have shown that large vertical buoyancy fluxes within the pycnocline have characteristic spatial and temporal scales of submesoscale processes that may be attributable to geostrophic frontogenesis (Yu et al., 2019; Siegelman et al., 2020). These studies raise the possibility that surface-enhanced submesoscale dynamics may influence the pycnocline directly through water mass exchange when there is a non-zero vertical velocity across the mixed layer base. 
There are two main processes that could adiabatically subduct water parcels from the mixed layer. The first is restratification of the mixed layer. As the mixed layer restratifies due to either heat fluxes or the slumping of isopycnals (Fox-Kemper et al., 2008; Mahadevan et al., 2012), some water parcels end up beneath the newly reformed mixed layer. The second process, which will be the focus of this paper, involves movement along sloping density surfaces. If a density surface from the pycnocline outcrops into the mixed layer, then water parcels can move adiabatically along that surface from the mixed layer into the interior (Stommel, 1979; Nurser \& Marshall, 1991; Gebbie, 2007; MacGilchrist et al., 2017; Canuto et al., 2018).

Frontal regions, where sloping isopycnals from the pycnocline outcrop in the surface mixed layer at the mesoscale and submesoscale, offer an advective pathway for the exchange of water across the base of the mixed layer (Ramachandran et al., 2014). Frontogenesis, which is the intensification of lateral buoyancy (or density) gradients at fronts, dynamically induces subduction (and upwelling) along the sloping isopycnal surfaces of the front and does not necessarily involve the shoaling of the mixed layer. Submesoscale instabilities can occur along strong mesoscale currents (Thomas \& Joyce, 2010; Gula et al., 2016), enhancing vertical motion and generating an asymmetry in the up-/down-ward motion, with subduction being more localized and intensified than upwelling.

Our objective is to study the dynamical processes and pathways through which the mixed layer and pycnocline connect in a frontal flow field and to provide insight into the subduction mechanisms when the mixed layer is not undergoing restratification. We use numerical modeling to interrogate the coupling between mesoscale and submesoscale processes along a strong mesoscale frontal meander with a 50-70 m deep mixed layer. The model is representative of the front between Atlantic and Mediterranean waters in the Alborán Sea, where the subduction of biogeochemical tracers was observed along a mesoscale frontal meander (Pascual et al., 2017; Ruiz et al., 2019). We do not force the model with winds or strong buoyancy fluxes at the surface, which would generate boundary layer turbulence with large vertical velocities in the mixed layer. Further, we do not resolve processes at scales smaller than $500 \mathrm{~m}$, such as symmetric instability. Instead, we study how unforced frontogenesis leads to subduction by following the evolution of dynamical and kinematic properties as water subducts out of the mixed layer along isopycnals.

Studying frontogenesis in the Lagrangian frame has several advantages. Firstly, the time history of processes on a water parcel as they evolve over a few days provides information about subduction. We are interested in transport, or the integrated motion over a few days, and not vertical velocity itself, which contains waves and other high frequency motions. Secondly, while we are interested in the downward motion of water, the along-front flow is faster by $3-4$ orders of magnitude. Hence, snapshot views of frontal 
cross-sections do not convey where the subducting water originates, or where it is headed. Thirdly, subduction does not occur everywhere along the front and to identify where it occurs, and on what spatial scales, we need to tag the water parcels that subduct. Following the advecting water parcels as they subduct allows us to construct a time history of the mechanisms. We define subduction as occurring when water parcels leave the mixed layer and travel at least $5 \mathrm{~m}$ below the mixed layer base into the pycnocline. By identifying the locations where water leaves the mixed layer, we examine the spatial scales of the process. The evolution of dynamical properties along water parcel trajectories reveals how frontogenesis acts to subduct water, but that there are a wide variety of subduction pathways along which the dominant frontogenetic and frontolytic factors can differ (Thomas, 2008; Barkan et al., 2019).

To begin, we discuss observations of subduction at the front between fresher (less dense) Atlantic water and saltier (denser) Mediterranean water from the Alboran Sea. Next, we offer some theoretical background based on which we develop hypotheses about the subduction processes. We then describe our idealized model and the Lagrangian methodology used for analysis. In our results, we present a statistical view, as well as a description of specific subduction pathways. Finally, we offer a discussion of our results and their implications in a broader context.

\section{Observational motivation}

Observations show that coherent subducted water masses are ubiquitous at strong fronts (Thomas \& Joyce, 2010; Pascual et al., 2017). In March and April of 2019 we embarked on an observational campaign to study the pathways of vertical transport of natural tracers from the surface ocean to the interior. We conducted hydrographic surveys on board the N/O Pourquoi Pas? from March 28-April 11 at strong mesoscale and submesoscale fronts in the Alborán Sea which is the westernmost part of the Mediterranean (Mahadevan et al., 2020). We measured vertical profiles of conductivity, temperature, and pressure using an Oceansciences underway CTD system in tow-yo mode at a spatial resolution of around $1 \mathrm{~km}$ while the ship was transiting across fronts (Johnston et al., 2019). Ocean velocities was measured from a $150 \mathrm{kHz}$ vessel-mounted ADCP.

The Western Alborán Gyre is formed by the mesoscale meander of the baroclinically unstable front between the saltier resident Mediterranean water and the fresher Atlantic water that enters through the strait of Gibralter (Figure 1A; longitudes $3.5 \mathrm{~W}$ to $5.5 \mathrm{~W})$. We traversed across the front several times, and Figure 1B shows, as an example, the hydrography from a section across the northern edge of the Western Alborán Gyre. The density gradient at the front is mostly due to salinity. Variations in temperature along a density surface are indicative of a different water mass that has intruded 
A
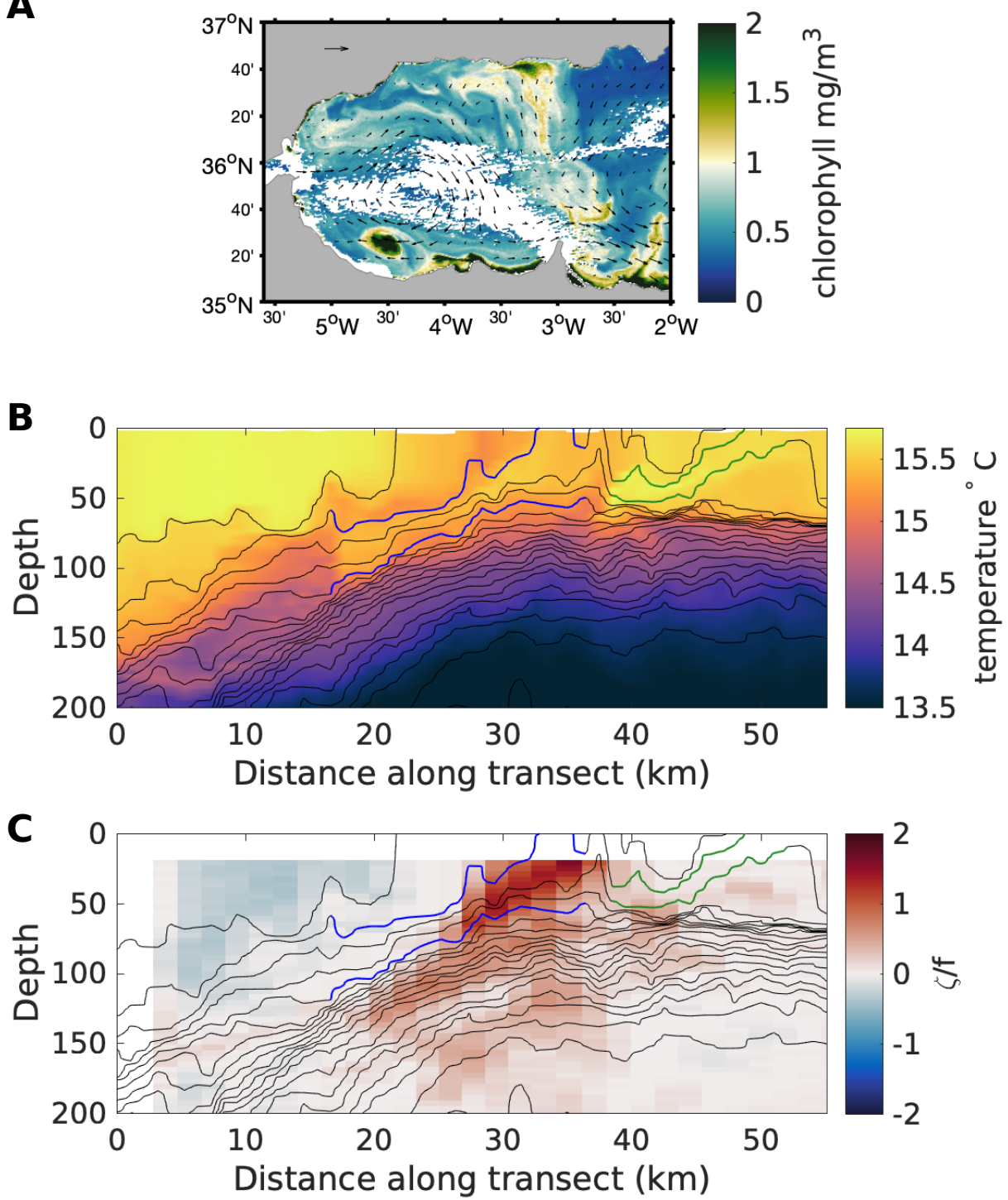

Figure 1. (a) MODIS Aqua satellite image of chlorophyll in the Alborán Sea on March 28, 2019. The geostrophic currents from AVISO (arrows) show the anticyclonic Western Alborán Gyre. The chlorophyll (in color) shows the influence of frontal dynamics at the gyre edge with frontal waves on the northern edge of the gyre. The CALYPSO cruise on the $N / O$ Pourquois Pas? surveyed the front transiting from south to north along the yellow line on March 30, 2019. (b) Transect of temperature (color) from an underway CTD with density contours at intervals of $0.1 \mathrm{~kg} / \mathrm{m}^{3}$. Subducted water masses are identified by temperature variations along an isopycnal surface. Two warm intrusions are highlighted by demarcating their bounding isopycnals in blue. (c) Transect of relative vorticity computed from the along-track gradient of the horizontal velocity normal to the ship section. Velocity measurements are from a vessel-mounted ADCP. 
through subduction and undergone stirring. There are multiple anomalously warm intrusions that extend from the surface into the pycnocline along isopycnals. Though these intrusions are visible in the cross-front direction, they are also expected to be moving rapidly in the along-front direction (out of the page in Figure 1B). Casts from a shipboard CTD show that these temperature anomalies are associated with unusually high fluorescence and low apparent oxygen utilization for the depth at which they occur, adding support to the idea that these are recently subducted, photosythetically productive, water masses. The along-track vorticity, which, despite neglecting cross-track gradients is a good estimate of the relative vertical vorticity because the ship traverses across the front, has surface-intensified cyclonic values at the center of the front (Figure 1C). On the dense side of the front, the vorticity is cyclonic, reaching $\approx 2 f$ at the center of the front, while on the light side of the front the vorticity is weakly anticyclonic.

The surface chlorophyll image shows high chlorophyll on the gyre edge that forms frontal waves or cusp-like features (Figure 1A), one of which is sampled by the ship transect. The feature on the northern flank of the front is found to be an eddy, $10 \mathrm{~km}$ in diameter and $70 \mathrm{~m}$ deep (Figure 1B). There is an anomalously warm intrusion of water wrapped around the submesoscale eddy on the dense side of the front, which extends from the surface to the upper pycnocline (Figure 1B). Despite the light core, this eddy has cyclonic vorticity (Figure 1C); the cusps in the chlorophyll image also suggest cyclonic rotation. A similar feature is found in the modeling study that follows. Another temperature intrusion is co-located with the high relative vorticity at the center of the front, where density surfaces from the upper pycnocline outcrop (Figure 1B,C). The intrusion extends $100 \mathrm{~m}$ in the vertical and $30 \mathrm{~km}$ in the north-south direction along density surfaces. On the deep end of this temperature intrusion, the feature has anticyclonic vorticity and reduced stratification.

These observations reveal pathways of natural tracers, or temperature anomaly on an isopycnal, from the surface mixed layer to the upper pycnocline that are coherent over scales of tens of kilometers. The vertical displacement associated with these features is on the order of 100 meters. Contrary to some previous observations that report subduction of low potential vorticity (PV) water, these subducted features are associated with strong cyclonic vorticity and are moderately stratified (Beaird et al., 2016; Archer et al., 2020). We use a process study model to examine the role that unforced frontal dynamics might have played in these observed subduction events, elaborate on the dynamical mechanisms of subduction, and describe the role of along-front variability in subduction from the surface mixed layer to the interior. 


\section{Theoretical background}

The lateral buoyancy (and density) gradient at ocean fronts can be intensified through the mechanism of frontogenesis (McWilliams, 2021). Here, buoyancy $b \equiv-\frac{g}{\rho_{0}}\left(\rho-\rho_{0}\right)$, where $\rho$ is the potential density, $\rho_{0}=1027 \mathrm{~kg} \mathrm{~m}^{-3}$ is a reference potential density, and $g$ is the acceleration due to gravity. The vertical and horizontal buoyancy gradients are denoted by $N^{2}=b_{z}$ and $M^{2}=\left|\nabla_{h} b\right|$. Treating buoyancy, $b$, as a tracer, the Lagrangian rate of change of the horizontal buoyancy gradient $\nabla_{h} b$ can be expressed as

$$
\frac{D}{D t} \nabla_{h} b=\underbrace{\left(-u_{x} b_{x}-v_{x} b_{y},-u_{y} b_{x}-v_{y} b_{y}\right)}_{\mathbf{Q}}-N^{2} \nabla_{h} w+\kappa_{H} \nabla_{h}^{2} \nabla_{h} b+\kappa_{V} \partial_{z z} \nabla_{h} b
$$

where $\nabla_{h}$ is the horizontal gradient operator in the $x-y$ plane and $D / D t \equiv \partial_{t}+u \partial_{x}+$ $v \partial_{y}+w \partial_{z}$ is the material derivative. Here, $\kappa_{H}$, the horizontal diffusivity and $\kappa_{V}$, the vertical diffusivity, are treated as homogeneous and constant. The vector $\mathbf{Q}$ on the right hand side of (1) is the tendency of advection to strengthen or weaken buoyancy gradients in the $x$ and $y$ directions and can be decomposed into geostrophic and ageostrohic contributions $\mathbf{Q}=\mathbf{Q}_{\mathbf{g}}+\mathbf{Q}_{\mathbf{a}}$ by using the respective gesotrophic or ageostrophic components of the horizontal velocity $(u, v)=\left(u_{g}, v_{g}\right)+\left(u_{a}, v_{a}\right)$. The square of the frontogenetic tendency (a scalar quantity) is given by

$$
\frac{1}{2} \frac{D}{D t}\left|\nabla_{h} b\right|^{2}=\underbrace{\mathbf{Q}_{\mathbf{g}} \cdot \nabla_{h} b}_{\text {geostrophic }}+\underbrace{\mathbf{Q}_{\mathbf{a}} \cdot \nabla_{h} b}_{\text {ageostrophic }}-\underbrace{N^{2} \nabla_{h} w \cdot \nabla_{h} b}_{\text {vertical }}+\underbrace{\kappa_{H} \nabla_{h}^{2} \nabla_{h} b \cdot \nabla_{h} b}_{k_{h}}+\underbrace{\kappa_{V} \partial_{z z} \nabla_{h} b \cdot \nabla_{h} b}_{k_{v}} .
$$

The large-scale straining that intensifies buoyancy gradients disrupts the thermal wind balance and generates ageostrophic circulation in the vertical plane (Hoskins \& Bretherton, 1972). The resulting vertical velocity, $w$, can be diagnosed from the observed frontogenetic strain (Hoskins et al., 1978) using the Omega equation

$$
N^{2} \nabla_{h}^{2} w-f_{0} \partial_{z z} w=2 \nabla_{h} \cdot \mathbf{Q}
$$

where $f_{0}$ is a reference Coriolis parameter. For a more detailed derivation see Section 13.3 of Hoskins and James (2014). In the quasigeostrophic formulation of the Omega equation, $\mathbf{Q}=\mathbf{Q}_{\mathbf{g}}$ contains only geostrophic velocities $\left(\mathbf{u}_{\mathbf{g}}\right)$, so the ageostrophic velocity and the vertical velocities are forced by only geostrophic straining. The lack of a feedback from ageostrophic velocities generated by frontogenesis causes both cyclonic and anticyclonic vorticity increase at the same rate and results in symmetric upwelling and downwelling (Hoskins \& Bretherton, 1972), both of which are not true at the oceanic submesoscale (Shcherbina et al., 2015).

As the relative vorticity increases, the quasigeostrophic Omega equation fails to accurately diagnose vertical velocities. The semigeostrophic Omega equation includes a feed- 
back between the ageostrophic velocity and the frontal intensity by allowing for advection of buoyancy and geostrophic velocities by the combined geostrophic and ageostrophic velocities. The non-linear feedback on the relative vorticity is evident from the Lagrangian rate of change of the absolute vorticity. Assuming adiabatic dynamics, the rate of change of the vertical component of the relative vorticity $(\zeta)$ is dominated by the vortex stretching and tilting terms on the right hand side of

$$
\frac{\mathrm{D}(f+\zeta)}{\mathrm{D} t}=(f+\zeta) \frac{\partial w}{\partial z}+\frac{1}{\rho^{2}}\left(\frac{\partial \rho}{\partial x} \frac{\partial p}{\partial y}-\frac{\partial \rho}{\partial y} \frac{\partial p}{\partial x}\right) .
$$

At surface convergences (positive $w_{z}$ ), the near surface vertical velocity is downwards (negative) and the relative vorticity increases exponentially. However, at divergences (negative $\left.w_{z}\right)$, the absolute vorticity $(f+\zeta)$ decreases and approaches zero, which slows the rate of decrease of relative vorticity. In addition, symmetric instability limits the relative vorticity to $\zeta \geq-f$.

The vertical structure of the vertical velocity depends on the stratification, the vorticity, and PV, which combines both buoyancy and velocity gradients. Both the stratification and PV gradients are typically large at the base of the mixed layer. PV and vorticity gradients are typically large at fronts. The ageostrophic overturning diagnosed by the semigeostrophic Omega equation is skewed with larger magnitude downward velocities and larger magnitude cyclonic vorticity than the quasigeostrophic solution. (Hoskins, 1982). This can be intuitively understood through a transformation into geostrophic coordinates, which compresses the horizontal scale of the ageostrophic overturning and aligns the upwelling branch of the overturning with isopycnal surfaces. An alternative vertical velocity diagnostic equation, the Eliassen-Sawyer equation (Eliassen, 1949; Sawyer, 1956), which is also an elliptic equation forced by the $\mathbf{Q}$ vector, reveals the links between vertical velocity and both the relative vorticity and PV. Vertical velocity is enhanced in regions with low $\mathrm{PV}$, and when the $\mathrm{PV}$ is constant, in regions with cyclonic relative vorticity due to reduced horizontal length scales (Thomas, 2008).

As a water parcel is transported by the ageostrophic circulation from the surface mixed layer into the stratified interior, the dynamical properties change on the water parcel. For example, $N^{2}$ on the water parcel increases and the relative vorticity on the water parcel must decrease ("vortex squashing") to conserve PV (Gent \& Mcwilliams, 1990; Wang, 1993; Spall, 1995). This ignores the horizontal components of the PV, $q_{h}$, which may be significant in areas with strong lateral density gradients. If $q_{h}$ becomes increasingly negative during subduction, then $\zeta$ would not decrease as much as would be expected from the vertical component alone.

The quasi- and semi-geostrophic theories outlined above are two dimensional and neglect along front curvature. However, the shape of the jet affects the frontogenetic tendency (McWilliams et al., 2019; Buckingham et al., 2021). At submesoscale fronts, the 


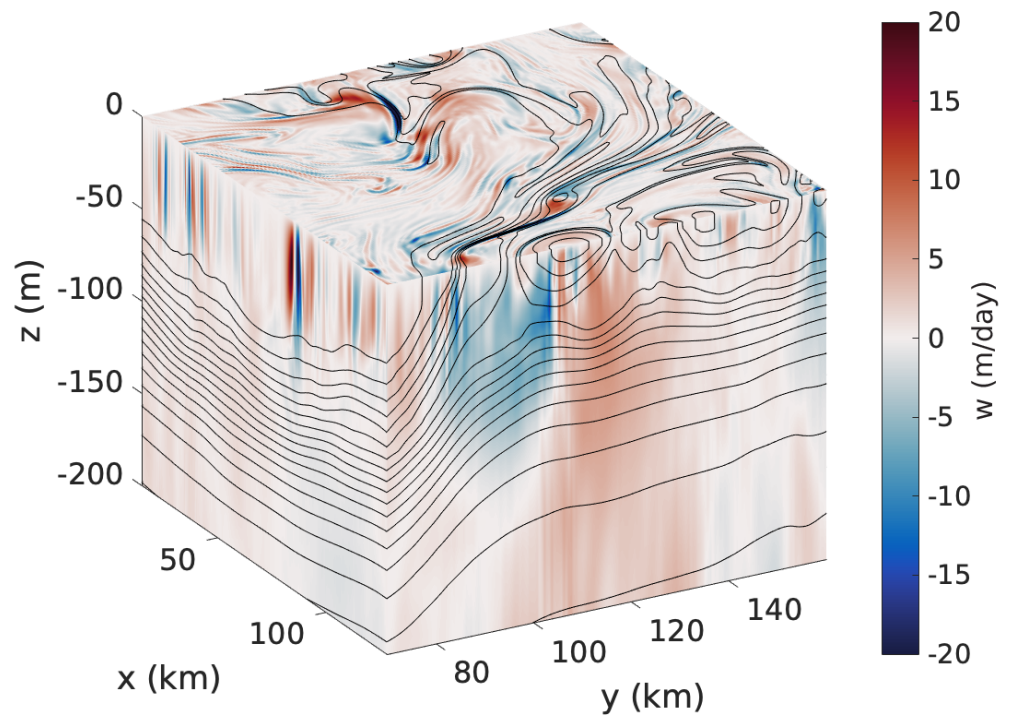

Figure 2. Vertical velocity with density contours on day 47.5. The vertical velocity that is shown at the surface is the 5 meter vertical velocity. Vertical velocity is shown in meters/day, with a saturated color scale.

curvature can be of the same scale as the cross-frontal scale, necessitating analysis of threedimensional processes. Additionally, frontogenesis is classically studied in cases with a deformation flow, but in a strong mesoscale front, the horizontal shear can also contribute to frontogensis (McWilliams, 2021). Moreover, diabatic processes and mixing are particularly important at the sharp fronts that are present at submesoscales (Giordani et al., 2006).

\section{Methods}

A three-dimensional numerical model is used to explore the dynamical mechanisms for subduction from the mixed layer into the pycnocline in the absence of strong surface forcing (wind stress or cooling). Our strategy is to follow water parcels and track their properties as they are subducted. By analyzing the kinematic and hydrographic properties in the Lagrangian frame as water parcels are subducting, we aim to statistically identify the characteristics and evolution of different subduction events.

\subsection{Model set up}

We simulate a front using the non-hydrostatic Process Study Ocean Model (PSOM) (Mahadevan et al., 1996a, 1996b; PSOM, 2020) in a zonal periodic channel. In the merid- 
ional direction, the model is initialized with the observed pycnocline structure of the mesoscale front on the edge of the Eastern Alborán Gyre in the Western Mediterranean and a 5070 meters deep mixed layer, typical of late-winter and early-spring conditions. The initial condition has a small-amplitude meander with one wavelength in the zonal direction to nudge the model to develop the large-scale meandering structure that is observed in the Alborán Sea. The model domain is centered at $36.9^{\circ} \mathrm{N}$. The inertial period is 20 hours.

The model domain extends $128 \mathrm{~km}$ in the (periodic) $x$-direction and $206 \mathrm{~km}$ in the $y$-direction (with closed walls) and $1000 \mathrm{~m}$ in depth. The horizontal resolution is $500 \mathrm{me}-$ ters, with a stretched grid in $y$ that attains a spacing of $2 \mathrm{~km}$ within $40 \mathrm{~km}$ of the southern and northern solid boundaries. There are 64 vertical levels on a stretched grid with grid spacing ranging from $0.5 \mathrm{~m}$ at the surface to $54 \mathrm{~m}$ at depth. The model timestep is 108 seconds. The horizontal diffusion is $1 \mathrm{~m}^{2} / \mathrm{s}$. The vertical diffusion has a constant value of $10^{-5} \mathrm{~m}^{2} / \mathrm{s}$. The model has a flat bottom and a linear bottom drag of $10^{-4} \mathrm{~m} / \mathrm{s}$. The model forced with weak cooling at a rate of $15 \mathrm{~W} / \mathrm{m}^{2}$ at the surface to maintain the mixed layer. The density is adjusted to a stable state by convective adjustment.

\subsection{Particle tracking}

Particle trajectories are used to identify subduction locations and study the evolution of dynamical properties along water parcel trajectories. Particles are advected offline from the model integration of momentum using an implementation of the Vries and Döös (2001) particle advection algorithm in Python (Dever \& Essink, 2020). The particles are advected using instantaneous velocity fields from the three-dimensional model saved every 3 hours and interpolated linearly to intermediate times. Particle trajectories integrated offline for 10 days (with 3-hourly model output) do not differ significantly from those calculated online in the model. For our study, we seed 12,700 each day at a spacing of $1 \mathrm{~km}$ at 5 meters depth from model days 44 to 62 . The particles are seeded across the whole domain. A total of 228,600 particles are used in this study. Tracers and velocities are interpolated from the model grid onto the particle positions using tri-linear interpolation. All gradients are computed on the model grid and then interpolated onto the particle positions.

\subsection{Tracers}

Similar to the particles, we advect 2 tracers offline with the model's advection routine and a time step of 108 seconds. The 3-hourly model output that was saved is interpolated in time onto the time step of the tracer advection model. 
A mixed layer tracer is used to diagnose the subduction rates and validate the particle results (Figure S1). This tracer is initialized with a value of 1 in the mixed layer and 0 outside the mixed layer. At every time step, the tracer concentration is instantaneously restored to 1 in the local mixed layer, which is recomputed every time step. It is not restored below the mixed layer.

A depth tracer is used to calculate the vertical transport rate over a time interval $\Delta t$. Since the tracer is continuous, it allows us to calculate variance spectra of the vertical transport rate as a function of horizontal wavenumber. The depth tracer is initialized on model day 43.75 (time $t_{0}$ ) with a value that equals its vertical position $z$, such that $\operatorname{Tr}\left(x, y, z, t_{0}\right)=z\left(t_{0}\right)$ in meters. The vertical transport rate $\left(w^{\Delta t}\right)$ over a time interval $\Delta t$ is computed as the difference between the tracer value (in meters) at $t_{0}+\Delta t$ and $t_{0}$ as

$$
w^{\Delta t}=\frac{\operatorname{Tr}\left(x, y, z, t_{0}+\Delta t\right)-\operatorname{Tr}\left(x, y, z, t_{0}\right)}{\Delta t} .
$$

The two-dimensional $(x-y)$ isotropic spectra of $w^{\Delta t}$ is computed using the package pyspec (Rocha, 2015).

\section{Results}

\subsection{Subduction rate}

The model domain contains a front within the pycnocline, with frontal isopycnals outcropping in the mixed layer, which ranges from $70 \mathrm{~m}$ on the light side of the front to $50 \mathrm{~m}$ on the dense side of the front. During the spin up phase, the front first develops mixed layer submesoscale instabilities. The mixed layer depth (defined as where the local density exceeds the surface density by $0.03 \mathrm{~km} / \mathrm{m}^{3}$ ) shoals to as little as 5 meters along the front, but maintains a depth of 50-70 meter away from the front. By day 20, mesoscale baroclinic instability develops (Figure 2). This progression of instabilities is consistent with previous studies on linear unstable modes: a smaller-scale, faster growing mixed layer mode and a larger scale pycnocline mode (Boccaletti et al., 2007; Callies et al., 2016). During the analysis period (model days 44 to 62), instabilities at both the mesoscale and submesoscale are present, but the regions where the local Rossby number $\left(R o=\frac{\zeta}{f}\right)$ is large, $R o \gtrsim 1$, are mostly localized around the mesoscale front.

Mixed layer water subducts into the pycnocline at a rate of $0.2-0.3 \mathrm{~Sv}$ over the $82,560 \mathrm{~km}^{2}$ domain over course of the analysis period. The subduction rate is computed as the rate of change of the volume of mixed layer water present below the mixed layer. When the subducted volume is normalized by the area of the domain, it amounts to $25 \mathrm{~m}$ of the mixed layer being subducted over a 3-month period (the approximate duration of the winter and early spring conditions simulated here) or $100 \mathrm{~m}$ over a year (if the same sub- 

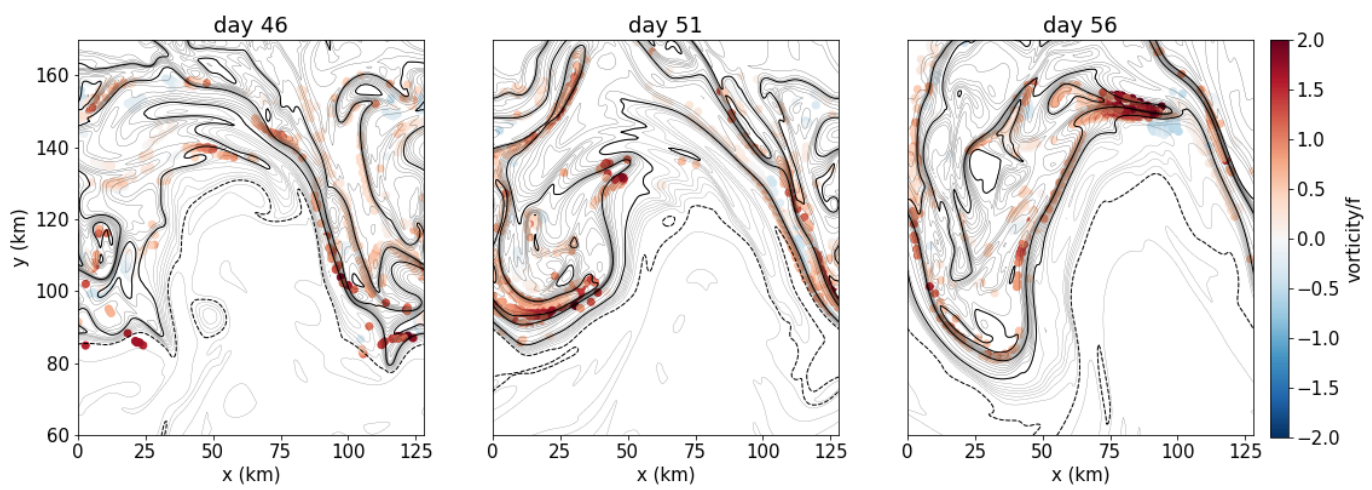

Figure 3. Positions $(x-y)$ of particles on the day that they subduct out of the mixed layer.

The particles are colored by their relative vorticity, with red referring to cyclonic, and blue to anti-cyclonic vorticity. Density at $5 \mathrm{~m}$ depth is contoured (thin lines CI $=0.02 \mathrm{~kg} / \mathrm{m}^{3}$, thick lines $\mathrm{CI}=0.2 \mathrm{~kg} / \mathrm{m}^{3}$ ). Dashed (solid) contours are lighter (denser) than the average surface density. Particles are subducting along the dense side of the fronts where the lateral buoyancy gradient is strongest, and most of the particles have cyclonic relative vorticity. The subduction locations are coherent and elongated in the along-front direction.

duction rate acts over the year). The subduction rate is diagnosed using the mixed layer tracer and is consistent with past mesoscale and submesoscale resolving simulations. (Gebbie, 2007; Canuto et al., 2018).

The largest values of vertical velocity in this simulation are 30-40 meters/day. Stronger submesoscale vertical velocities have been both observed and modeled (Mahadevan et al., 2010; DAsaro et al., 2018). The vertical velocity is expected to be stronger when the model includes wind forcing, a parameterization of boundary layer turbulence, deeper mixed layer, stronger mesoscale jet, or smaller value of horizontal eddy diffusivity (Wang, 1993).

\subsection{Coherence of subduction}

In the Lagrangian analysis, we consider subduction to occur when a water parcel that was initially in the mixed layer, moves 5 meters below the mixed layer and remains below the mixed layer for the remainder of the 10 day trajectory. We identify the water parcels' subduction location (horizontal position) and time (model day) (Figure 3). This is done by comparing the particles' $z$ location with the local mixed layer depth for each grid cell in the $x-y$ plane and interpolated onto the particle locations at every time step. Of all of the particles seeded evenly across the domain at 5 meters and reseeded 

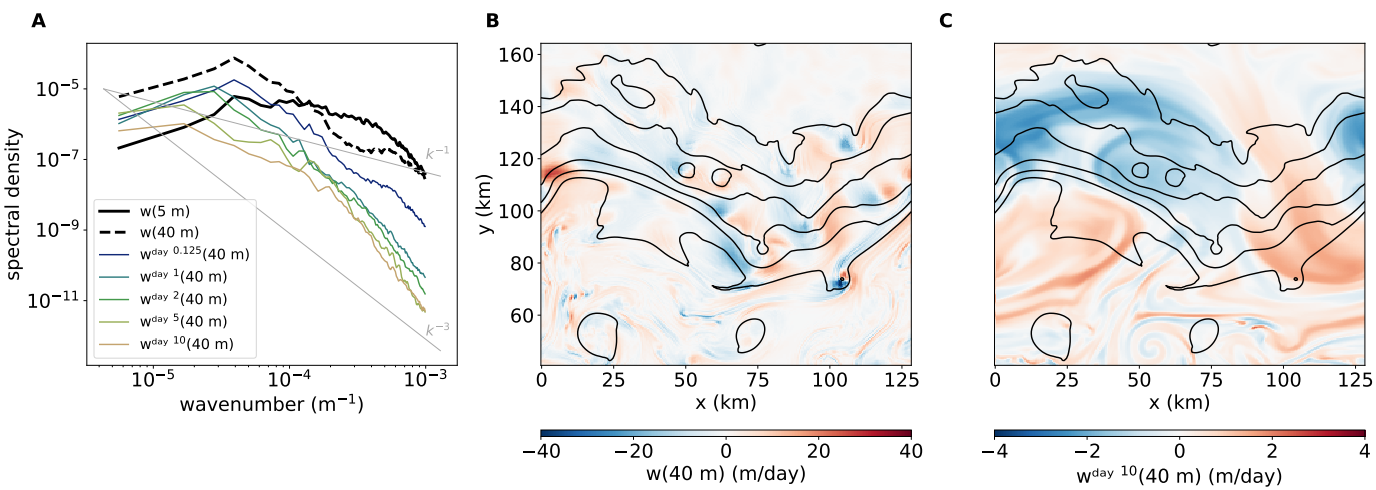

Figure 4. (A) Vertical velocity and vertical transport isotropic wavenumber variance spectra. The black lines are the vertical velocity spectrum at (solid) 5 meters depth and (dashed) 40 meters depth. The colored lines show the spectra of the vertical transport at 40 meters depth calculated over a range of time intervals according to (5). The grey lines are guides for $k^{-1}$ and $k^{-3}$ slopes. (B) Vertical velocity at 40 meters depth. (C) Vertical transport over 10 days at 40 meters depth.

daily, $7.7 \%$, or 18,740 , subduct out of the mixed layer. The subduction occurs in localized regions along the front, which leads to coherent features during subduction.

The complex frontal density structure results in a rich variety of features on which water parcels subduct (Figure 3). Subduction occurs at the strongest density gradients, which are outcrops of the pycnocline front, and at mixed layer fronts. The subduction locations are almost all located on the dense side (cyclonic side) of the main pycnocline fronts, but intermittently along the front, and in transient features associated with submesoscale filaments and eddies.

Where the water parcels end up after subduction is determined by how subduction interacts with the flow beneath the mixed layer. We use tracer spectra to quantify the transport across different spatial and temporal scales (Figure 4). The near-surface $(5 \mathrm{~m})$ vertical velocity has variability across a wide range of spatial scales, including small scales, as evidenced by the nearly flat spectrum. Since the vertical velocity goes to zero at the surface, the vertical velocity at 5 meters depth is approximately equal to the surface horizontal divergence multiplied by the depth, $\Delta z$,

$$
\left.w \approx \nabla_{h} \cdot \mathbf{u}_{\mathbf{h}}\right|_{z=0}(\Delta z) .
$$

At shallow depths, the vertical velocity spectrum $\left\langle w^{2}\right\rangle$ is therefore related to the horizontal velocity spectrum $\left\langle\mathbf{u}_{\mathbf{h}}{ }^{2}\right\rangle$ by

$$
\left\langle w^{2}\right\rangle \sim\left\langle\nabla \cdot \mathbf{u}_{\mathbf{h}}{ }^{2}\right\rangle \sim k^{2}\left\langle\mathbf{u}_{\mathbf{h}}{ }^{2}\right\rangle .
$$


At 40 meters depth, which is near the base of the mixed layer, the horizontal velocity has a spectral slope between $k^{-3}$ and $k^{-4}$, but the vertical velocity spectrum is steeper than predicted by (7) and not directly related to the local divergence of the horizontal velocity near the surface, because the divergence has variable magnitude and sign between 40 meters and the surface (Figure 4A).

The spectrum of the vertical transport defined by (5) has lower power than the vertical velocity spectrum because the instantaneous vertical velocity has more extreme values than the time integrated vertical transport. Over time intervals of less than one day, the transport spectrum differs more from the vertical velocity spectrum at high wavenumbers (small spatial scales). Much of the difference is due to the influence of internal waves on the vertical velocity spectrum, but not the transport spectrum (Balwada et al., 2018). Over time intervals of 5-10 days, the transport spectrum flattens mostly in the smaller wavenumber range. The result is a relatively flat $\left(\sim k^{-1}\right)$ spectrum at spatial scales approximately between 10 and $100 \mathrm{~km}$, expected when interior quasigeostrophic turbulence stirs passive tracers along isopycnal surfaces (Vallis, 2006). At smaller scales, the spectrum is steeper due to a transition in dynamics and likely an increased role for threedimensional effects, submesoscale stirring, and coherent transport (Spiro Jaeger et al., 2020). Subduction also occurs at these smaller scales.

\subsection{Lagrangian description of subduction dynamics}

The time evolution of dynamical properties on the water parcels undergoing subduction from the mixed layer is examined by compositing Lagrangian time histories on a shifted time axis with time zero being the day on which the water parcel was subducted (Figure 5). The solid line in Figure 5 is the median of each property (lateral and vertical buoyancy gradients, relative vorticity, vertical velocity, PV, cyclostrophic acceleration, and frontogenetic terms) and the shaded region is the interquartile range. The properties on half of the subducting particles fall within the interquartilie range, but half fall outside this range. The median of the dynamical properties on the quickly subducting water parcels (water parcels that reach at least $20 \mathrm{~m} /$ day downward vertical velocity) is shown in the dashed line. The time prior to subduction when particles are in the mixed layer is indicated as negative, time zero represents a transition as particles subduct, and the positive time axis shows the period of their evolution after subduction. The evolution of the water parcel properties during subduction sets the properties of the subducted water masses. As expected for downward motion from the mixed layer to the pycnocline, the stratification $\left(N^{2}\right)$ increases (Figure 5A) and the vertical velocity increases in magnitude (downwards) (Figure 5B). The ratio of the magnitude of the lateral to vertical buoyancy gradient, $M^{2} / N^{2}$, is the isopycnal slope. The isopycnal slope is large in the 

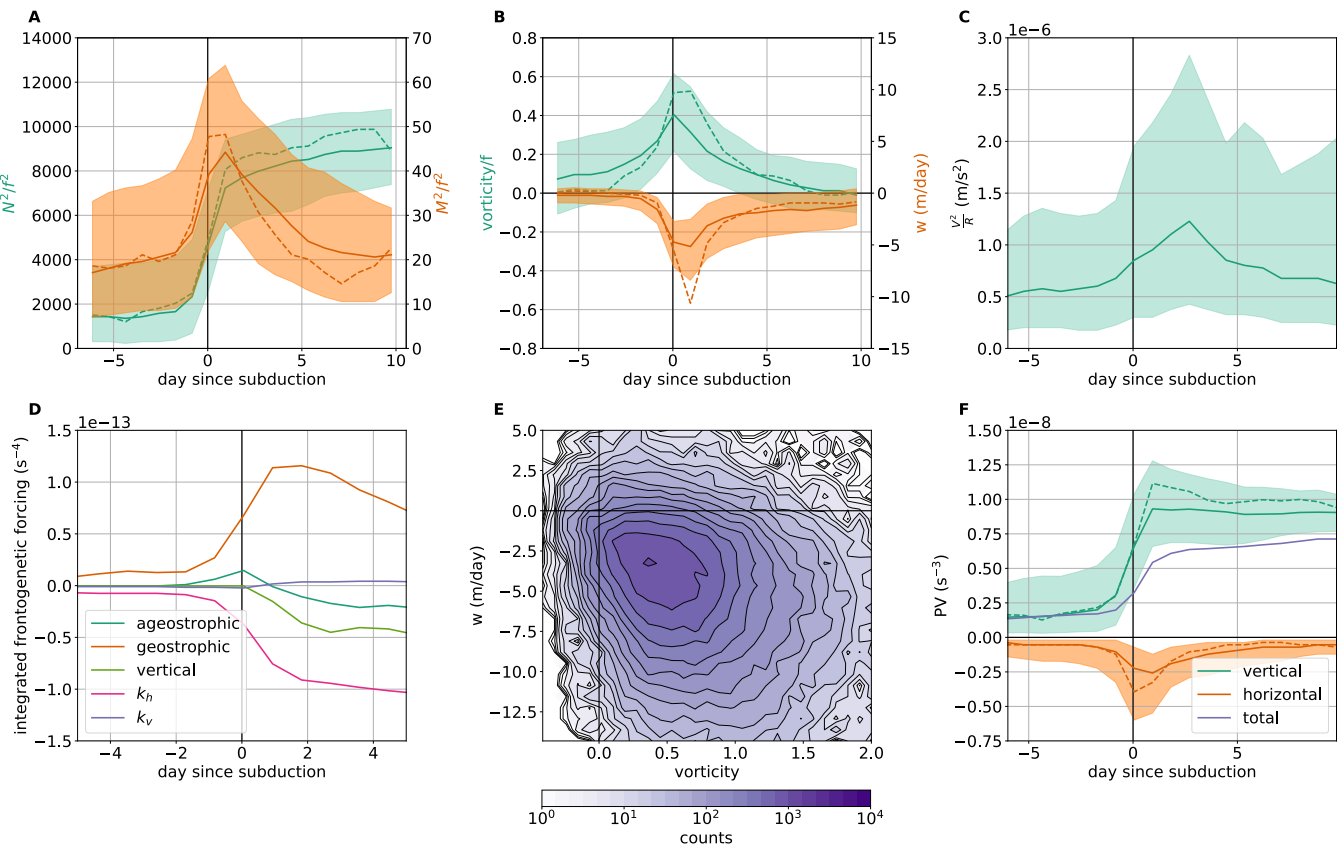

Figure 5. Lagrangian evolution of dynamical quantities as water parcels are subducted. All trajectories are composited onto a shifted time axis where time zero is the subduction time of the water parcel (defined as the time when it moves from the mixed layer to 5 meters below the mixed layer depth). The solid line is the median value. The shaded region encloses the first and third quartiles of all subducted particles. Approximately $7 \%$ of all of the particles subduct. The dashed line shows the median of all particles that subduct faster than $20 \mathrm{~m} /$ day. The reference Coriolis frequency used to normalize properties is $f=10^{-4} \mathrm{~s}^{-1}$. (A) Stratification $\left(N^{2} / f^{2}\right)$ (left axis, green) and lateral buoyancy gradient $\left(M^{2} / f^{2}\right)$ (right axis, orange) (B) Relative vorticity normalized by the Coriolis frequency (left axis, green) and vertical velocity (right axis, orange) (C) Non-linear acceleration due to curved particle trajectories. The radius of curvature $(R)$ is calculated using velocities and accelerations averaged over 15 hours on particle trajectories. (D) Various contributions to frontogenesis, represented by the terms on the right hand side of Equation (2) integrated in time along particle trajectories. The lines show the median values of all subducted particles on a shifted time axis. Positive values are frontogenetic and negative values are frontolytic. The $\mathbf{Q}$-vector is split into geostrophic and ageostrophic components. The third term is frontogenesis by the vertical velocity ("vertical"). The fourth term is horizontal diffusion $\left(k_{h}\right)$. The fifth term is vertical diffusion $\left(k_{v}\right)$. (E) Two dimensional histogram showing the relationship between the vertical component of relative vorticity (normalized by $f$ ) and the vertical velocity on particles during the 20 hours prior to subduction. (F) Vertical and horizontal contributions to the PV. The purple line is the median of the total PV. 
mixed layer and during subduction, which mostly occurs along steeply sloping isopycnal surfaces ( $M^{2}$ and $N^{2}$ both increase). The stratification continues to increase as water parcels subduct, but the lateral buoyancy gradient peaks during subduction and then gradually decreases (Figure 5A) as subducted water parcels enter a region of higher stratification. This restratification on a Lagrangian trajectory does not necessarily mean that the larger-scale front restratifies. Instead, water parcels are moving along density surfaces into a more stratified region. The mixed layer volume stays relatively constant and does not decrease throughout the analysis period (Figure S2).

The Ertel potential vorticity (PV) is conserved on the water parcels, except during the subduction event, when diabatic processes come into play. In the mixed layer, the $\mathrm{PV}$ is near zero due to the low stratification and the negative contribution from vertical shear at strong fronts. During subduction, the total PV on the water parcels increases abruptly (Figure 5F). The mixed layer tracer also reveals the same magnitude of increase in PV during subduction in this model (Figure S1), suggesting that the Lagrangian particles stay in the same water parcel during subduction. The subducted water mass still has lower PV on average than the interior water mass. The relevance of diabatic processes in subduction suggests that improved representation of the frontal arrest process (Bodner et al., 2020) and boundary layer turbulence (Gula et al., 2014) could have large implications for exchange between the mixed layer and interior.

The PV can be split into a vertical (vortical) contribution $\left(q_{v}\right)$ and a horizontal (baroclinic) contribution $\left(q_{h}\right)$. The vertical contribution $q_{v}$ remains elevated after the water parcels have subducted. The magnitude of $q_{h}$, which is negative, increases transiently as the water parcels subduct (Holmes et al., 2014). The increase in the magnitude of $q_{h}$ and decrease in the vertical component of relative vorticity $(\zeta)$ do not counter the increase in $q_{v}$ that arises from the increase in stratification, $N^{2}$.

\subsubsection{Frontogenesis}

The intensification of the lateral buoyancy gradient prior to and during subduction demonstrates that frontogenesis plays an important role in subduction (Figure 5A). On average, frontogenesis occurs here due to straining by the geostrophic velocities. The ageostrophic strain also contributes to average frontogenesis during subduction (Figure 5D; Equation 2). After subduction, frontolysis is mainly due to the ageostrophic overturning circulation and horizontal diffusion (Figure 5D). In situations with stronger vertical velocity, the ageostrophic frontogenesis terms could be more important (Barkan et al., 2019). We describe a few cases where ageostrophic frontogenesis dominates in submesoscale features (Section 5.4). 
Concurrent with frontogenesis, the vertical component of the relative vorticity, $\zeta$, increases rapidly on water parcels as they approach the subduction location, after which their $\zeta$ decreases (Figure 5B). Nearly all of the water parcels have cyclonic vorticity when they initially subduct out of the mixed layer (Figure 3) and about half develop anticyclonic vorticity by the end of the trajectory (Figure 5B). The third quartile of $\zeta$ on subducting water parcels reaches $\sim 0.6 f$. The average rate of subduction on trajectories is fairly slow, at 1-4 meters per day. However, the vertical velocity, $w$, during and immediately after subduction can be large $(20-30 \mathrm{~m} /$ day $)$. At the time of subduction, $\zeta$ and $w$ are negatively correlated, but the largest values of $w$ have a significant vorticity range (Figure 5E). On average, $\zeta$ on water parcels peaks ahead of the downward $w$ (Figure 5B) due to the relationships between vorticity and vertical velocity (Equation 4). At the sea surface, $w$ approaches zero, but $\zeta$ often reaches a maximum; vortex stretching is due to the vertical shear of the vertical velocity.

\subsubsection{Curvature of trajectories}

The large values of cyclonic vorticity on the dense side of the front contribute to strengthening the PV gradient and make the front susceptible to baroclinic and barotropic instabilities that manifest as frontal waves. The increase in cyclonic vorticity on the water parcels is due to two factors: (i) shear on the edge of the jet, which is a $2 \mathrm{D}$ mechanism (cross-front and in the vertical) and is described by the semi-geostrophic Omega equation, and (ii) curvature of the trajectories, a 3D process that includes along-front variability and impacts the dynamics through a cyclostrophic acceleration, $\frac{V^{2}}{R}$ where $V$ is the velocity magnitude and $R=\frac{\left(u^{2}+v^{2}\right)^{3 / 2}}{u v_{t}-v u_{t}}$ is the radius of curvature. If the cyclostrophic term is the same order of magnitude as the Coriolis term, the balanced velocity will be in gradient wind balance rather than geostrophic balance. The cyclostrophic term is larger when the flow is more non-linear. On the particle trajectories, the cyclostrophic acceleration increases prior to subduction, peaks 2-3 days after subduction on average, and then decreases (Figure 5C). The water parcels have cyclonic vorticity during subduction, so the cyclostrophic term decelerates the velocity relative to the geostrophic velocity, resulting in a convergence and downwelling along the particle trajectories. In this way, the spiralling of water parcels helps to maintain downward transport. Both the cyclostrophic acceleration (McWilliams et al., 2019) and the conversion from the baroclinic to the vortical contributions of the PV (Thomas, 2008) reveal the importance of along-front curvature in driving subduction. 

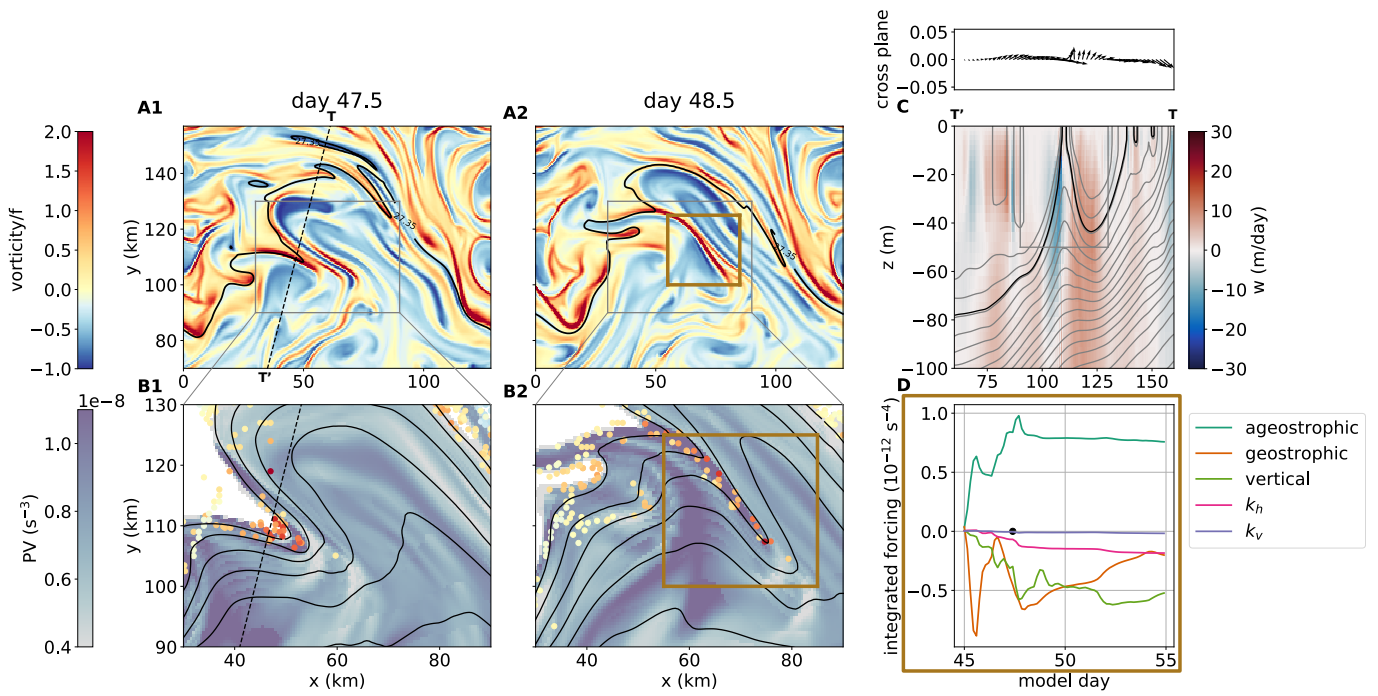

Figure 6. A submesocale filament as a pathway for subduction from the mixed layer. The evolution of a cyclonic filament is shown in panels A, B. (A) Surface relative vorticity normalized by the Coriolis frequency on days 47.5 (1) and 48.5 (2). The contour is $\sigma=27.35$. (B) PV on the $\sigma=27.35$ surface. The black contours are isopycnal height at 10 meter intervals. All particles shown have density within $0.01 \mathrm{~kg} / \mathrm{m}^{3}$ of the isopycnal surface and subduct below the mixed layer during their trajectory. The particles are colored by their relative vorticity. (C) Lower panel: Cross section of the vertical velocity in meters/day on day 47.5 along the black dashed line $\mathrm{T}^{\prime}-\mathrm{T}$ in panel $\mathrm{A}(1)$. Contours are isopycnals. The black contours $\sigma=27.8$. Upper panel: surface horizontal velocity in the along plane direction (x-axis) and cross plane direction. Downwards in the cross plane direction is out of the page (positive $\mathrm{x}$ direction). (D) Mean timeintegrated frontogenetic forcing on the particles within the orange box in panels A,B. Positive slopes are frontogenetic and negative slopes are frontolytic. Contributions to frontogenesis are split into the terms on the right hand side of Equation (2). The black dot on the $\mathrm{x}$-axis indicates the time of subduction. 

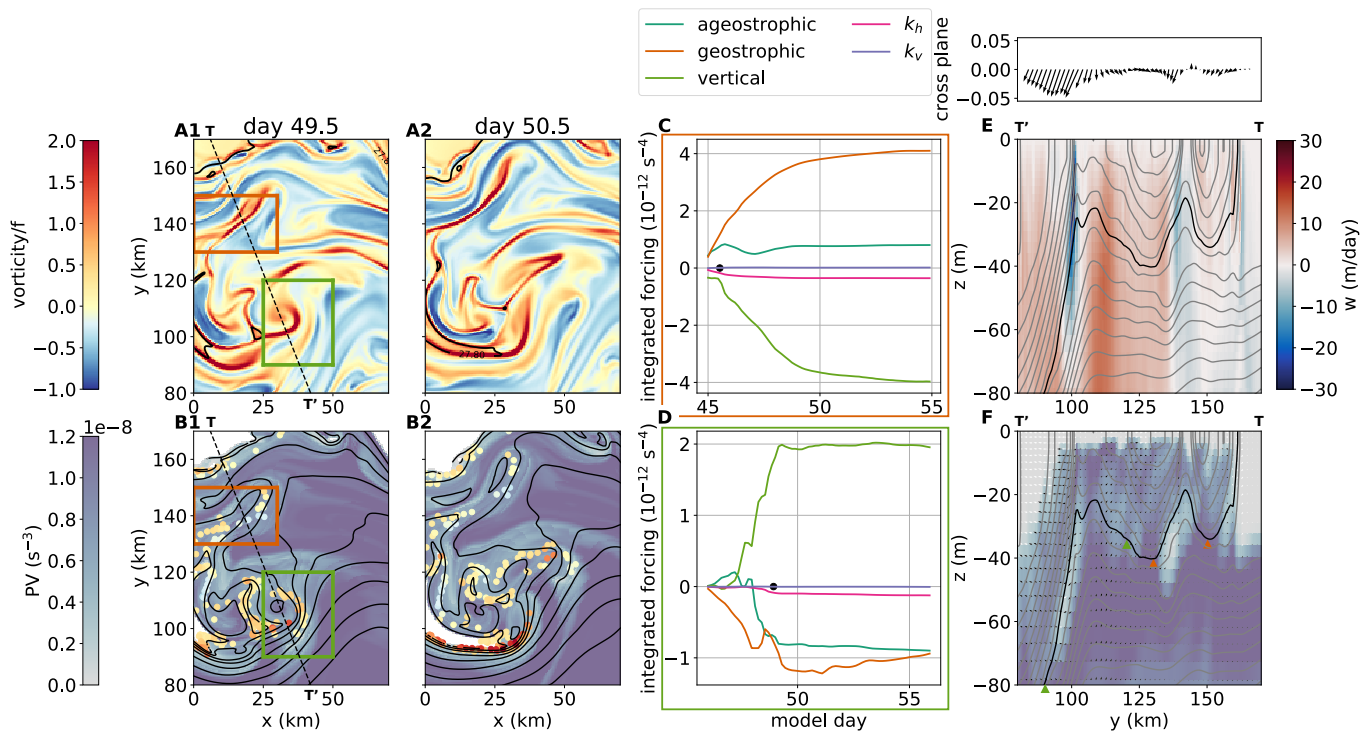

Figure 7. Two specific pathways for subduction from the mixed layer form an intrapycnocline eddy (orange box) and cut-off cyclone (green box). (A) Surface relative vorticity normalized by the Coriolis frequency on days 49.5 (1) and 50.5 (2). The contour is $\sigma=27.8$. (B) PV on the $\sigma=27.8$ surface. The black contours are isopycnal height at 10 meter intervals. All particles shown have density within $0.01 \mathrm{~kg} / \mathrm{m}^{3}$ of the isopycnal surface and subduct below the mixed layer during their trajectory. The particles are colored with their relative vorticity. (C,D) Contributions to frontogenesis split into the terms on the right hand side of Equation (2). The forcing due to each term is integrated in time along each subducting particle trajectory. (C) Mean timeintegrated frontogenetic forcing on the particles within the orange box in panels A,B (D) Mean time-integrated frontogenetic forcing on the particles within the green box in panels $\mathrm{A}, \mathrm{B}$. Positive slopes are frontogenetic and negative slopes are frontolytic. The black dot on the $\mathrm{x}$-axis indicates the time of subduction. (E, F) Cross sections on day 49.5 at the black dashed line on panels A,B. Contours are isopycnals. The black contour is $\sigma=27.8$. (E) Upper panel: surface horizontal velocity in the along plane direction (x-axis) and cross plane direction. Downwards in the cross plane direction is out of the page (positive $\mathrm{x}$ direction). Lower panel: Vertical velocity in meters per day. (F) PV with velocity vectors. The low PV anomaly between the orange markers is an intrapycnocline eddy formed by subduction. The green and orange triangles show the y locations of the green and orange boxes in panels A1,B1. 


\subsection{Subduction by submesoscale features}

Examining particle trajectories on isopycnal surfaces reveals some of the submesoscale processes that enhance subduction. Restratification and along-isopycnal stirring may work in tandem to promote subduction. As the base of the mixed layer restratifies (Fox-Kemper et al., 2008), water parcels are trapped in a transition layer with reduced turbulence (Shcherbina \& D'Asaro, 2020; Taylor et al., 2020) and are more likely to subduct along isopycnals into the pycnocline.

While water parcels move upward and downward in the pycnocline as they transit through the crest and trough of a mesoscale meander (Bower et al., 1985; Bower, 1991; Samelson, 1992), the along-front structure facilitates the growth of submesoscale features that contribute to subduction from the mixed layer. Subduction is analyzed using equation (2) in three submesoscale features that are found to differ in their frontogenesis mechanisms. The processes described here differ from subduction in other physical situations that are dominated by mixed layer eddies (Boccaletti et al., 2007; Omand et al., 2015; Shcherbina et al., 2015; McWilliams, 2016) or symmetric instability (Thomas et al., 2013; Erickson \& Thompson, 2018). Here, subduction from the surface mixed layer to the interior occurs through the combination of mesoscale and submesoscale processes.

\subsubsection{Submesoscale filaments}

As the vorticity rapidly increases at the mesoscale front due to geostrophic frontogenesis, the front develops wave-like features at the sharpest density gradient (Figure 6A) due to horizontal shear and baroclinicity. As the wavy instabilities grow, they further intensify due to ageostrophic secondary circulations, and wrap into submesoscale vortices or elongate into filaments. Submesoscale dense filaments are known to rapidly intensify through a dual frontogenetic process called filamentogenesis (McWilliams et al., 2009; Gula et al., 2014).

A filament generated by geostrophic and ageostrophic frontogenesis has large cyclonic vorticity (Figure 6A) and downwelling vertical velocity at its center (Figure 6C). Water parcels subduct out of the mixed layer along a sloping isopycnal ( Figure 6B) during the development of the filament. There is upwelling on either side of the subduction region that brings up high PV water that is mixed into the subduction region both adibatically along the isopycnal surface (Figure 6B) and diabatically (not shown) resulting in a subducting water mass that has high PV relative to surrounding water on the same isopycnal surface (Figure 6B). After subduction, the water parcels are transported more than $80 \mathrm{~km}$ laterally across the domain and continue to subduct as the cyclonic 
filament relaxes. This example reveals a pathway to subduct anomalously high PV attained through diapycnal mixing with surrounding water.

Here, (Figure 6D) the filament intensifies by both geostrophic and ageostrophic frontogenesis (the rate of change of the integrated frontogenetic forcing is positive) (Barkan et al., 2019) and decays due to geostrophic frontolysis, horizontal diffusion and vertical transport. Other model studies with $500 \mathrm{~m}$ grid resolution, but smaller horizontal diffusivity and boundary layer turbulence parameterized by KPP, have found that filamentogenesis is halted by secondary instabilities of the filament rather than by diffusion (Gula et al., 2014; Barkan et al., 2019), in contrast to lower resolution models (1.5 km).

Previous observational and modeling studies have shown that cold (cyclonic) submesoscale filaments in the Gulf Stream and Antarctic Circumpolar Current can contribute to exchange between the surface and pycnocline (Gula et al., 2014; Klymak et al., 2016; Taylor et al., 2018).

\subsubsection{Intrapycnocline eddies}

Quasigeostrophic theory predicts that subduction occurs due to geostrophic frontogenesis, which generates ageostrophic horizontal and vertical velocities. As low PV surface mixed layer water crosses the front it subducts along an isopycnal surface while conserving quasigeostrophic $\mathrm{PV}, q=\frac{f+\zeta}{H}$, where $H$ is the layer thickness. If the mixed layer is thicker than isopycnal layers in the thermocline, the subducted water mass becomes an anticyclonic intrapycnocline eddy as it is compressed during subduction (Spall, 1995). The length scale of the intrapycnocline eddy is expected to be the internal deformation radius. The radius of deformation of the mixed layer is $\frac{N_{0} D}{f} \approx 3 \mathrm{~km}$ where $N_{0}^{2}=10^{-4} \mathrm{~s}^{-1}$ is the reference stratification, $D=30 \mathrm{~m}$ is the mixed layer depth, and $f=10^{-4} \mathrm{~s}^{-1}$.

An intrapycnocline eddy can be identified in a cross section as a low PV anomaly, which in Figure $7 \mathrm{~F}$ is shown bounded by the orange triangles and has a radius slightly smaller than $3 \mathrm{~km}$. The formation of a low PV intrapycnocline eddy on the $\sigma=27.8$ isopycnal surface is highlighted in the brown box in Figure 7B. The water parcels that become this intrapycnocline eddy are subducted from a region of large cyclonic vorticity (Figure 7A,B: orange box) due to geostrophic frontogenesis with some contribution from ageostrophic frontogenesis (Figure 7C, equation (2)). The water parcels subduct on a dense (cyclonic) filament that outcrops at the center of the front. The intrapycnocline eddy that forms during subduction moves towards the dense side of the front and is elongated as it subducts into a region where the vertical branch of the ageostrophic circulation is frontolytic. The water parcels, which initially have large values of cyclonic vorticity, develop weakly anticyclonic vorticity within one day (vorticity is in colors on 
the water parcels in Figure 7B). The intrapycnocline eddy has a cyclonic surface expression (Figure 7A).

Intrapycnocline eddies have been observed near fronts (Archer et al., 2020) and anticyclonic submesoscale vortices, which were likely generated at fronts have been observed more generally. These eddies trap material in the interior and are potentially important for transporting heat, salt, and biological communities (Frenger et al., 2017). In this study, we observe that the subducted water mass fills the center of the subducted feature, supporting non-local coherent material transport.

\subsubsection{Cut-off cyclones}

The mixed layer base, not just the sea surface, is involved in the formation of a submesoscale cyclone (Figure 7A,B: green box) as differential vertical motion intensifies the front by tilting the stratification at the mixed layer base onto the horizontal (Figure 7D). The cyclonic vorticity is largest on the edges rather than the center of this eddy (Figure 7A: green box). The core of the submesoscale cyclone has high PV, rather than the low PV that would be expected from an intrapycnocline eddy. Low PV mixed layer water parcels leave the mixed layer around the edges of the cyclone. While subduction is $3 \mathrm{D}$ in the surface layer, once water parcels leave the mixed layer, they are transported along isopycnal surfaces and the subduction has a more $2 \mathrm{D}$ character resulting in a low PV water mass at depth that has weakly cyclonic vorticity (Figure 7E, near $100 \mathrm{~km}$ ).

The dynamics and kinematics of the modeled cyclone reflect the formation process of cutoff cyclones, or cutoff lows, in atmospheric dynamics (Rotunno et al., 1994). Cutoff lows are known to be important for stratosphere-troposphere exchange (Holton et al., 1995; Fuenzalida et al., 2005). Related dynamics in the ocean may naturally be expected to be relevant for exchange between the mixed layer and thermocline. A similar feature to the modeled cyclone was observed in a section across the western Alborán Gyre (Figure 1B,C, near $50 \mathrm{~km}$ ). Frontal waves and eddies that are qualitatively similar to this modeled feature and the feature on the Alborán Gyre observations have been observed previously, mostly from satellites and photographs from space shuttles, and have been attributed to both shear instability and baroclinic instability (Munk et al., 2000; Yin \& Huang, 2016; Klymak et al., 2016). In both cases, the waves are observed to become unstable in 2-3 days and have wavelengths of $20-30 \mathrm{~km}$, consistent with the modeled features. 


\section{Discussion}

This process study reveals the challenge of separating submesoscale and mesoscale processes, which may feedback on each other. The mesoscale front provides sloping surfaces along which water parcels can be exported into the pycnocline. Subduction patterns are largely driven by along-front variability of the mesoscale meander, which generates ageostrophic secondary circulations through frontogenesis and is shaped by those same ageostrophic secondary circulations (McWilliams et al., 2019). A variety of submesoscale features, either cyclonic or anti-cyclonic, support subduction that occurs along high or low PV pathways. Volume anomalies that are subducted from the surface mixed layer into the pycnocline can have anomalously low stratification and PV compared to surrounding waters and thereby develop anticyclonic relative vorticity (Pollard \& Regier, 1992). However, subduction of water mass anomalies and biogeochemical tracers can occur along sloping density surfaces even without generating a volume anomaly and therefore could also occur along high PV pathways (Freilich \& Mahadevan, 2019). High PV water parcels are upwelled and subducted along isopycnal surfaces in regions with vertical circulation that is so rapid that surface forcing would not have time to remove PV at the surface. At the submesoscale, the cyclonic curvature of water parcel trajectories that encounter frontal waves would alter the thermal wind balance and modify the ageostrophic overturning. The presence of the mesoscale front may in some situations enhance submesoscale instability (Rotunno et al., 1994), but mesoscale fronts may also stabilize the flow through strain or barotropic shear (Gula et al., 2016; Taylor et al., 2018; Stamper et al., 2018). While subduction locations may be short lived and the residence time in subduction locations very short, along-front variability in both horizontal and vertical velocity patterns breaks the periodicity of the meander (Bower, 1991; Samelson, 1992) resulting in longer-term subduction.

These results have implications for the parameterization of subduction processes, since they are found to be are both local and non-local. If the subduction were completely incoherent it could be appropriately modeled as a diffusive process. If subduction took place through a steady overturning process, it would either be completely reversible or only associated with restratification. We find that the exchange across the mixed layer base occurs at $\mathcal{O}(10 \mathrm{~km})$ scales and is important for supplying oxygen to the pycnocline and nutrients to the mixed layer. The spatial scale of the subduction affects the upper ocean thermohaline structure (Cole \& Rudnick, 2012; Spiro Jaeger et al., 2020) and biogeochemical tracer distributions (Erickson \& Thompson, 2018). Improved process level understanding of exchange across the mixed layer base could lead to improved estimates of upper ocean productivity and pycnocline ventilation (Jin et al., 2007; Llanillo et al., 2018). 
Eddy fluxes at the meso- and submeso-scale are increasingly recognized as important for the transport of water masses and biogeochemical tracers from the surface to the interior (Omand et al., 2015; Balwada et al., 2018; Canuto et al., 2018; Resplandy et al., 2019). Submesoscale processes will be most important during times of the year and in locations with deep mixed layers, namely the winter and early spring but may only affect oxygen and carbon transport on annual timescales if the water parcels are transported below the deepest wintertime mixed layer. (Palevsky \& Nicholson, 2018) The seasonal restratification of the mixed layer is an important process for subduction of carbon and oxygen into the pycnocline, but the stratified waters may be re-entrained into the mixed layer the following winter Transport of water masses across the mixed layer base without restratifying the mixed layer is a mechanism for transport below the deepest mixed layer on interannual timescales.

\section{Conclusions}

Subduction processes from the mixed layer into the interior are organized by, but not entirely controlled by, the mesoscale meandering jet. By analyzing the trajectories of water parcels we find that submesoscale features generated through baroclinic instability of the mesoscale front open up pathways into the interior. As water parcels subduct, they experience increased horizontal and vertical buoyancy gradients and a peak in the relative vorticity. While geostrophic frontogenesis drives the majority of subduction in this study, we also outline the importance of ageostrophic and three-dimensional processes for subduction and illustrate these subduction processes with specific examples. Even in locations of net mesoscale upwelling, submesoscale dynamics subduct water from the mixed layer. Subduction from the mixed layer is mostly localized at the strong mesoscale front, but occurs episodically along that front due to frontogenetic processes with high spatial and temporal variability. This variability reduces the likelihood of re-entrainment of water parcels into the mixed layer and determines the spatial scale of exchange between the surface and interior. The subduction is coherent on spatial scales of order 1$10 \mathrm{~km}$, as was observed in the Western Mediterranean. The dynamical subduction by the submesoscale has a similar subduction rate to larger scale processes, but is not resolved in global models.

\section{Acknowledgments}

We thank Mathieu Dever and Sebastian Essink for providing the particle tracking code, Eric D'Asaro and Jing He for comments on an earlier version of this manuscript, and Dhruv Balwada for a constructive review that led to substantial improvements. We 
thank the CALYPSO science team for all of their contributions to data collection and for insightful conversations. We especially acknowledge Shaun Johnston for providing the underway CTD data displayed in Fig. 1B,C and Margaret Conley and Mathieu Dever for collaborating on processing the underway CTD data. We thank the captain and crew of the N/O Pourquoi Pas? for their invaluable assistance at sea. This research was funded by the ONR CALYPSO DRI grant N00014-16-1-3130. MAF was partially funded by a Martin Fellowship from MIT. The codes to reproduce the model and particle runs can be found at https://doi.org/10.5281/zenodo.3902273 and the code and data to reproduce the figures can be found at https://doi.org/10.5281/zenodo.4302604 and the links therein.

\section{References}

Archer, M., Schaeffer, A., Keating, S., Roughan, M., Holmes, R., \& Siegelman, L. (2020). Observations of submesoscale variability and frontal subduction within the mesoscale eddy field of the Tasman Sea. Journal of Physical Oceanography, $50(5), 1509-1529$.

Badin, G., Tandon, A., \& Mahadevan, A. (2011). Lateral mixing in the pycnocline by baroclinic mixed layer eddies. Journal of Physical Oceanography, 41(11), 2080-2101.

Balwada, D., Smith, K. S., \& Abernathey, R. (2018). Submesoscale vertical velocities enhance tracer subduction in an idealized Antarctic Circumpolar Current. Geophysical Research Letters, 45(18), 9790-9802.

Barkan, R., Molemaker, M. J., Srinivasan, K., McWilliams, J. C., \& DAsaro, E. A. (2019). The role of horizontal divergence in submesoscale frontogenesis. Journal of Physical Oceanography, 49(6), 1593-1618.

Beaird, N., Rhines, P., \& Eriksen, C. (2016). Observations of seasonal subduction at the Iceland-Faroe front. Journal of Geophysical Research: Oceans, 121(6), 4026-4040.

Boccaletti, G., Ferrari, R., \& Fox-Kemper, B. (2007). Mixed layer instabilities and restratification. Journal of Physical Oceanography, 37(9), 2228-2250.

Bodner, A. S., Fox-Kemper, B., Van Roekel, L. P., McWilliams, J. C., \& Sullivan, P. P. (2020). A perturbation approach to understanding the effects of turbulence on frontogenesis. Journal of Fluid Mechanics, 883.

Bosse, A., Testor, P., Mortier, L., Prieur, L., Taillandier, V., d'Ortenzio, F., \& Coppola, L. (2015). Spreading of Levantine Intermediate Waters by submesoscale coherent vortices in the northwestern mediterranean sea as observed with gliders. Journal of Geophysical Research: Oceans, 120(3), 1599-1622. 
Bower, A. S. (1991). A simple kinematic mechanism for mixing fluid parcels across a meandering jet. Journal of Physical Oceanography, 21(1), 173-180.

Bower, A. S., Rossby, H. T., \& Lillibridge, J. L. (1985). The Gulf Streambarrier or blender? Journal of Physical Oceanography, 15(1), 24-32.

Buckingham, C. E., Gula, J., \& Carton, X. (2021). The role of curvature in modifying frontal instabilities. part i: Review of theory and presentation of a nondimensional instability criterion. Journal of Physical Oceanography, 51(2), 299-315.

Callies, J., Flierl, G., Ferrari, R., \& Fox-Kemper, B. (2016). The role of mixed-layer instabilities in submesoscale turbulence. Journal of Fluid Mechanics, 788, 541.

Canuto, V., Cheng, Y., \& Howard, A. (2018). Subduction by submesoscales. Journal of Geophysical Research: Oceans, 123(12), 8688-8700.

Cole, S. T., \& Rudnick, D. L. (2012). The spatial distribution and annual cycle of upper ocean thermohaline structure. Journal of Geophysical Research: Oceans, $117(\mathrm{C} 2)$.

DAsaro, E. A., Shcherbina, A. Y., Klymak, J. M., Molemaker, J., Novelli, G., Guigand, C. M., ... Özgökmen, T. (2018). Ocean convergence and the dispersion of flotsam. Proceedings of the National Academy of Sciences, 115(6), $1162-1167$.

Dever, M., \& Essink, S. $\quad(2020,6)$ Offline particle tracking. Retrieved from https://doi.org/10.5281/zenodo. 3902282

Eliassen, A. (1949). The quasi-static equations of motion with pressure as independent variable. Grøndahl \& Sons boktr., I kommisjon hos Cammermeyers boghandel.

Erickson, Z. K., \& Thompson, A. F. (2018). The seasonality of physically driven export at submesoscales in the northeast Atlantic Ocean. Global Biogeochemical Cycles, 32(8), 1144-1162.

Fox-Kemper, B., Ferrari, R., \& Hallberg, R. (2008). Parameterization of mixed layer eddies. Part I: Theory and diagnosis. Journal of Physical Oceanography, 38(6), $1145-1165$.

Freilich, M. A., \& Mahadevan, A. (2019). Decomposition of vertical velocity for nutrient transport in the upper ocean. Journal of Physical Oceanography, $49(6)$, $1561-1575$.

Frenger, I., Bianchi, D., Oschlies, A., \& Waschkowitz, C. (2017). Subsurface coherent eddies: Hypoxic stewpots and biogeochemical highways. EGUGA, 2236.

Fuenzalida, H. A., Sánchez, R., \& Garreaud, R. D. (2005). A climatology of cut- 
off lows in the southern hemisphere. Journal of Geophysical Research: Atmospheres, $110(\mathrm{D} 18)$.

Gebbie, G. (2007). Does eddy subduction matter in the northeast Atlantic Ocean? Journal of Geophysical Research: Oceans, 112(C6).

Gent, P. R., \& Mcwilliams, J. C. (1990). Isopycnal mixing in ocean circulation models. Journal of Physical Oceanography, 20(1), 150-155.

Giordani, H., Prieur, L., \& Caniaux, G. (2006). Advanced insights into sources of vertical velocity in the ocean. Ocean Dynamics, 56(5-6), 513-524.

Gula, J., Molemaker, M. J., \& McWilliams, J. C. (2014). Submesoscale cold filaments in the Gulf Stream. Journal of Physical Oceanography, 44 (10), 26172643.

Gula, J., Molemaker, M. J., \& McWilliams, J. C. (2016). Submesoscale dynamics of a Gulf Stream frontal eddy in the South Atlantic Bight. Journal of Physical Oceanography, 46(1), 305-325.

Haine, T. W., \& Marshall, J. (1998). Gravitational, symmetric, and baroclinic instability of the ocean mixed layer. Journal of Physical Oceanography, 28(4), 634658.

Holmes, R. M., Thomas, L. N., Thompson, L., \& Darr, D. (2014). Potential vorticity dynamics of tropical instability vortices. Journal of physical oceanography, $44(3), 995-1011$.

Holton, J. R., Haynes, P. H., McIntyre, M. E., Douglass, A. R., Rood, R. B., \& Pfister, L. (1995). Stratosphere-troposphere exchange. Reviews of Geophysics, $33(4), 403-439$.

Hoskins, B. J. (1982). The mathematical theory of frontogenesis. Annual review of fluid mechanics, 14(1), 131-151.

Hoskins, B. J., \& Bretherton, F. P. ～(1972). Atmospheric frontogenesis models: Mathematical formulation and solution. Journal of the Atmospheric Sciences, $29(1), 11-37$.

Hoskins, B. J., Draghici, I., \& Davies, H. (1978). A new look at the w-equation. Quarterly Journal of the Royal Meteorological Society, 104(439), 31-38.

Hoskins, B. J., \& James, I. N. （2014). Fluid dynamics of the mid-latitude atmosphere. John Wiley \& Sons.

Jin, X., Najjar, R., Louanchi, F., \& Doney, S. C. (2007). A modeling study of the seasonal oxygen budget of the global ocean. Journal of Geophysical Research: Oceans, 112(C5).

Johnston, T. S., MacKinnon, J. A., Colin, P. L., Haley, P. J., Lermusiaux, P. F., Lucas, A. J., ... Waterhouse, A. F. (2019). Energy and momentum lost to 
wake eddies and lee waves generated by the North Equatorial Current and tidal flows at Peleliu, Palau. Oceanography, 32(4), 110-125.

Klymak, J. M., Shearman, R. K., Gula, J., Lee, C. M., D’Asaro, E. A., Thomas, L. N., .. McWilliams, J. C. (2016). Submesoscale streamers exchange water on the north wall of the gulf stream. Geophysical Research Letters, 43(3), $1226-1233$.

Lévy, M., Bopp, L., Karleskind, P., Resplandy, L., Éthé, C., \& Pinsard, F. (2013). Physical pathways for carbon transfers between the surface mixed layer and the ocean interior. Global Biogeochemical Cycles, 27(4), 1001-1012.

Llanillo, P., Pelegrí, J. L., Talley, L., Peña-Izquierdo, J., \& Cordero, R. (2018). Oxygen pathways and budget for the eastern South Pacific oxygen minimum zone. Journal of Geophysical Research: Oceans, 123(3), 1722-1744.

MacGilchrist, G. A., Marshall, D. P., Johnson, H. L., Lique, C., \& Thomas, M.

(2017). Characterizing the chaotic nature of ocean ventilation. Journal of Geophysical Research: Oceans, 122(9), 7577-7594.

Mahadevan, A., Dasaro, E., Lee, C., \& Perry, M. J. (2012). Eddy-driven stratification initiates North Atlantic spring phytoplankton blooms. Science, 337(6090), $54-58$.

Mahadevan, A., Oliger, J., \& Street, R. (1996a). A nonhydrostatic mesoscale ocean model. Part II: Numerical implementation. Journal of Physical Oceanography, 26(9), 1881-1900.

Mahadevan, A., Oliger, J., \& Street, R. (1996b). A nonhydrostatic mesoscale ocean model. Part I: Well-posedness and scaling. Journal of Physical Oceanography, 26(9), 1868-1880.

Mahadevan, A., Pascual, A., Rudnick, D. L., Ruiz, S., Tintoré, J., \& DAsaro, E. (2020). Coherent pathways for vertical transport from the surface ocean to interior. Bulletin of the American Meteorological Society, 101(11), E1996E2004.

Mahadevan, A., \& Tandon, A. (2006). An analysis of mechanisms for submesoscale vertical motion at ocean fronts. Ocean Modelling, 14(3-4), 241-256.

Mahadevan, A., Tandon, A., \& Ferrari, R. (2010). Rapid changes in mixed layer stratification driven by submesoscale instabilities and winds. Journal of Geophysical Research: Oceans, 115(C3).

McWilliams, J. (2021). Oceanic frontogenesis. Annual Review of Marine Science, 13, 227-253.

McWilliams, J., Colas, F., \& Molemaker, M. (2009). Cold filamentary intensification and oceanic surface convergence lines. Geophysical Research Letters, 36(18). 
McWilliams, J., Gula, J., \& Molemaker, M. J. (2019). The Gulf Stream north wall: Ageostrophic circulation and frontogenesis. Journal of Physical Oceanography, 49(4), 893-916.

McWilliams, J. C. (2016). Submesoscale currents in the ocean. Proceedings of the Royal Society A: Mathematical, Physical and Engineering Sciences, 472(2189), 20160117.

Munk, W., Armi, L., Fischer, K., \& Zachariasen, F. (2000). Spirals on the sea. Proceedings of the Royal Society of London. Series A: Mathematical, Physical and Engineering Sciences, 456(1997), 1217-1280.

Nurser, A. G., \& Marshall, J. C. (1991). On the relationship between subduction rates and diabatic forcing of the mixed layer. Journal of Physical Oceanography, $21(12), 1793-1802$.

Omand, M. M., DAsaro, E. A., Lee, C. M., Perry, M. J., Briggs, N., Cetinić, I., \& Mahadevan, A. (2015). Eddy-driven subduction exports particulate organic carbon from the spring bloom. Science, 348(6231), 222-225.

Palevsky, H. I., \& Nicholson, D. P. (2018). The North Atlantic biological pump: insights from the Ocean Observatories Initiative Irminger Sea array. Oceanography, 31(1), 42-49.

Pascual, A., Ruiz, S., Olita, A., Troupin, C., Claret, M., Casas, B., ... Tintoré, J. (2017). A multiplatform experiment to unravel meso-and submesoscale processes in an intense front (AlborEx). Frontiers in Marine Science, 4, 39.

Pollard, R. T., \& Regier, L. A. (1992). Vorticity and vertical circulation at an ocean front. Journal of Physical Oceanography, 22(6), 609-625.

PSOM. (2020, 6). Retrieved from https://doi.org/10.5281/zenodo. 3902273

Ramachandran, S., Tandon, A., \& Mahadevan, A. (2014). Enhancement in vertical fluxes at a front by mesoscale-submesoscale coupling. Journal of Geophysical Research: Oceans, 119(12), 8495-8511.

Resplandy, L., Lévy, M., \& McGillicuddy Jr, D. J. (2019). Effects of eddy-driven subduction on ocean biological carbon pump. Global Biogeochemical Cycles, $33(8), 1071-1084$.

Rocha, C. B. (2015, 9). pyspec. Retrieved from https://doi.org/10.5281/zenodo .31596

Rotunno, R., Skamarock, W. C., \& Snyder, C. (1994). An analysis of frontogenesis in numerical simulations of baroclinic waves. Journal of the atmospheric sciences, 51 (23), 3373-3398.

Ruiz, S., Claret, M., Pascual, A., Olita, A., Troupin, C., Capet, A., ... others (2019). Effects of oceanic mesoscale and submesoscale frontal processes on 
the vertical transport of phytoplankton.

Journal of Geophysical Research: Oceans, 124(8), 5999-6014.

Samelson, R. (1992). Fluid exchange across a meandering jet. Journal of Physical Oceanography, 22(4), 431-444.

Sawyer, J. S. (1956). The vertical circulation at meteorological fronts and its relation to frontogenesis. Proceedings of the Royal Society of London. Series A. Mathematical and Physical Sciences, 234(1198), 346-362.

Shcherbina, A. Y., \& D'Asaro, E. A. (2020). Direct observations of submesoscale modulation of ocean surface boundary layer turbulence. In Ocean sciences meeting 2020 .

Shcherbina, A. Y., Sundermeyer, M. A., Kunze, E., DAsaro, E., Badin, G., Birch, D., ... Ledwell, J. R. (2015). The LatMix summer campaign: submesoscale stirring in the upper ocean. Bulletin of the American Meteorological Society, $96(8), 1257-1279$.

Siegelman, L., Klein, P., Rivière, P., Thompson, A. F., Torres, H. S., Flexas, M., \& Menemenlis, D. (2020). Enhanced upward heat transport at deep submesoscale ocean fronts. Nature Geoscience, 13(1), 50-55.

Skyllingstad, E. D., Duncombe, J., \& Samelson, R. M. (2017). Baroclinic frontal instabilities and turbulent mixing in the surface boundary layer. part II: Forced simulations. Journal of Physical Oceanography, 47(10), 2429-2454.

Smith, K. M., Hamlington, P. E., \& Fox-Kemper, B. (2016). Effects of submesoscale turbulence on ocean tracers. Journal of Geophysical Research: Oceans, 121(1), 908-933.

Spall, M. A. (1995). Frontogenesis, subduction, and cross-front exchange at upper ocean fronts. Journal of Geophysical Research: Oceans, 100 (C2), 2543-2557.

Spiro Jaeger, G., MacKinnon, J., Lucas, A., Shroyer, E., Nash, J., Tandon, A., ... Mahadevan, A. (2020). How spice is stirred in the Bay of Bengal. Journal of Physical Oceanography, 50(9), 2669-2688.

Stamper, M. A., Taylor, J. R., \& Fox-Kemper, B. (2018). The growth and saturation of submesoscale instabilities in the presence of a barotropic jet. Journal of Physical Oceanography, 48(11), 2779-2797.

Stanley, R. H., McGillicuddy Jr, D. J., Sandwith, Z. O., \& Pleskow, H. M.

Submesoscale hotspots of productivity and respiration: Insights from highresolution oxygen and fluorescence sections.

Deep Sea Research Part I: Oceanographic Research Papers, 130, 1-11.

Stommel, H. (1979). Determination of water mass properties of water pumped down from the Ekman layer to the geostrophic flow below. Proceedings of the 
National Academy of Sciences, 76(7), 3051-3055.

Taylor, J. R., Bachman, S., Stamper, M., Hosegood, P., Adams, K., Sallee, J.-B., \& Torres, R. (2018). Submesoscale rossby waves on the Antarctic Circumpolar Current. Science advances, 4(3), eaao2824.

Taylor, J. R., Smith, K. M., \& Vreugdenhil, C. A. (2020). The influence of submesoscales and vertical mixing on the export of sinking tracers in large-eddy simulations. Journal of Physical Oceanography, 50(5), 1319-1339.

Thomas, L. N. (2008). Formation of intrathermocline eddies at ocean fronts by wind-driven destruction of potential vorticity. Dynamics of atmospheres and oceans, 45(3-4), 252-273.

Thomas, L. N., \& Joyce, T. M. (2010). Subduction on the northern and southern flanks of the Gulf Stream. Journal of physical oceanography, 40(2), 429-438.

Thomas, L. N., Tandon, A., \& Mahadevan, A. (2008). Submesoscale processes and dynamics. Ocean modeling in an Eddying Regime, 177, 17-38.

Thomas, L. N., Taylor, J. R., Ferrari, R., \& Joyce, T. M. (2013). Symmetric instability in the Gulf Stream. Deep Sea Research Part II: Topical Studies in Oceanography, 91, 96-110.

Vallis, G. (2006). Atmospheric and ocean fluid dynamics. Cambridge University Press, 6, 74-75.

Verma, V., Pham, H. T., \& Sarkar, S. (2019). The submesoscale, the finescale and their interaction at a mixed layer front. Ocean Modelling, 140, 101400.

Vries, P., \& Döös, K. (2001). Calculating lagrangian trajectories using timedependent velocity fields. Journal of Atmospheric and Oceanic Technology, $18(6), 1092-1101$.

Wang, D.-P. (1993). Model of frontogenesis: Subduction and upwelling. Journal of Marine Research, 51(3), 497-513.

Wenegrat, J. O., Thomas, L. N., Gula, J., \& McWilliams, J. C. $\quad$ (2018). Effects of the submesoscale on the potential vorticity budget of ocean mode waters. Journal of Physical Oceanography, 48(9), 2141-2165.

Yin, W., \& Huang, D. (2016). Evolution of submesoscale coastal frontal waves in the east china sea based on geostationary ocean color imager observational data. Geophysical Research Letters, 43(18), 9801-9809.

Yu, X., Naveira Garabato, A. C., Martin, A. P., Buckingham, C. E., Brannigan, L., \& Su, Z. (2019). An annual cycle of submesoscale vertical flow and restratification in the upper ocean. Journal of Physical Oceanography, 49(6), $1439-1461$. 